\title{
Epidermal egr-like zinc finger protein of Drosophila participates in myotube guidance
}

\section{Götz Frommer, Gerd Vorbrüggen, Giora Pasca', Herbert Jäckle ${ }^{2}$ and Talila Volk'}

\author{
Abteilung Molekulare Entwicklungsbiologie, Max-Planck-Institut für \\ biophysikalische Chemie, Am Fassberg, D-37077 Göttingen, Germany \\ and ${ }^{1}$ Department of Molecular Genetics and Virology, \\ Weizmann Institute of Science, Rehovot 76100, Israel \\ ${ }^{2}$ Corresponding author
}

We have cloned and molecularly characterized the Drosophila gene stripe (sr) required for muscle-pattern formation in the embryo. Through differential splicing, $s r$ encodes two nuclear protein variants which contain a zinc finger DNA-binding domain in common with the early growth response (egr) family of vertebrate transcription factors. The $s r$ transcripts and their protein products are exclusively expressed in the epidermal muscle attachment cells and their ectodermal precursors, but not in muscles or muscle precursors. The results suggest that $s r$ activity induces a subset of ectodermal cells to develop into muscle attachment sites and to provide spatial cues necessary to orient myotubes along the basal surface of the epidermis to their targeted attachment cells.

Keywords: Drosophila myogenesis/muscle-attachment cells/myotube guidance/stripe mutant/zinc finger protein

\section{Introduction}

The body-wall musculature of the Drosophila embryo is composed of an elaborate pattern of segmentally repeated muscle fibers. Each of the $\sim 30$ distinct muscle fibers per hemisegment can be distinguished by shape, position and pattern of innervation. During mid-stages of embryogenesis, muscles derive through fusion of distinct myoblasts leading to the formation of syncytial myotubes at sites close to the epidermis (reviewed by Bate, 1993). Following somatic muscle cell determination and their initial arrangement, the resulting myotubes stretch and enlarge through continued fusion with myoblasts (Bate, $1990,1993)$. They extend growth-cone-like polar processes at their leading edges to encounter their specific epidermal muscle attachment sites in the epidermis, to form stable contact with these cells of ectodermal origin (Bate, 1993).

It is postulated that the intricate pattern of larval somatic musculature develops due to positional information maintained by the ectoderm during early as well as later stages of mesoderm development (Bate, 1993; Staehling et al., 1994; Frasch, 1995). Mutations in segment polarity genes cause the absence or the ectopic appearance of muscle attachment cells and result in a disorganized muscle pattern (Volk and VijayRaghavan, 1994). While it remains to be shown that the mutant effect is not due to the autonomous expression of the segment polarity genes within the mesoderm itself, an ectodermal contribution to the oriented growth of the myotubes seems likely. This assumption is consistent with earlier transplantation experiments with a different insect species (Williams and Caveney, 1980a,b) and with embryonic tissue culture experiments (Volk and VijayRaghavan, 1994), both suggesting that the oriented migration of myotubes depends on positional information provided by ectodermal cells.

It had recently been reported that the Drosophila gene stripe ( $s r$ ) is necessary for the establishment of the muscle pattern during embryogenesis (Volk and VijayRaghavan, 1994). $s r$ was initially identified through a weak mutation which shows a longitudinal 'stripe' covering the dorsal roof of the adult thorax (Bridges and Morgan, 1923). This stripe results from a reduction of the dorsal longitudinal muscles causing inability of adults to fly. Stronger, embryonic lethal $s r$ alleles, such as $s r^{155}$ (De La Pompa et al., 1989) and $s r$ deficiency mutant embryos, suggest that $s r$ is required for the establishment of the normal larval muscle pattern (Volk and VijayRaghavan, 1994). Here we report the cloning and a functional analysis of the $s r$ gene during embryogenesis. It transcribes two splicing variants encoding a unique triple zinc finger motif characteristic for the early growth response (egr)-family of vertebrate transcription factors (reviewed in Madden and Rauscher, 1993). Embryonic expression of $s r$ is restricted to the subset of ectodermal cells which give rise to the epidermal muscle-attachment cells. $s r$ function is required for the proper differentiation of these cells which are central for the establishment of the muscle pattern. Our results suggest that $s r$ enables epidermal cells to orient myotubes towards their targets, the muscle-attachment cells.

\section{Results}

Previous work indicated that a $s r$ mutant allele generated by P-element reversion causes embryonic lethality with no visible sign of defects except that embryos exert an irregular muscle pattern (Volk and VijayRaghavan, 1994). In order to assess $s r$ muscle function in more detail, we examined muscle development in embryos which were homozygous for the strong $s r^{155}$ allele or hemizygous for $s r^{155}$ in trans over a deficiency. This deficiency, Df(3R)DG4, uncovers the $s r$ locus by deleting the cytogenetic interval 90E1-2 to 90F3-11 on the third chromosome (Lindsley and Zimm, 1992). Figure 1 shows the arrangement of somatic muscles as visualized by antimyosin heavy chain antibodies at stage 16 (stages according to Campos-Ortega and Hartenstein, 1985) in wild-type and $s r$ mutant embryos. At a time when the myofibers of wild-type embryos were already anchored at 

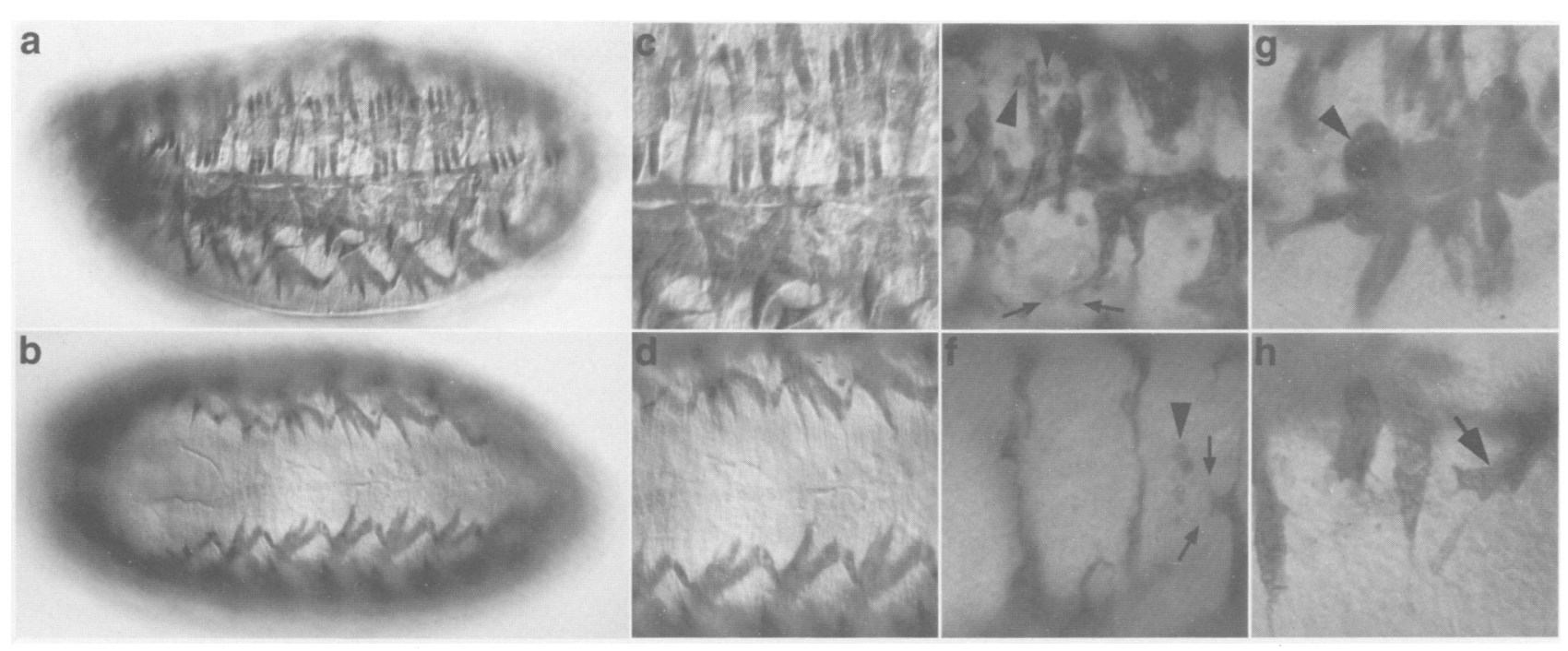

Fig. 1. Wild-type and $s r$ mutant myotube pattern visualized by anti-myosin heavy chain antibodies. (a) Lateral (dorsal side up) and (b) ventral view of the muscle pattern of wild-type embryos at stage 16; anterior is left. (c and d) Enlargements corresponding to three abdominal segment equivalents of the same embryos. (e and $\mathbf{f}$ ) Corresponding enlargements of $s r$ mutant $\left[s r^{155} / \mathrm{Df}(3) \mathrm{DG} 4\right]$ showing myotubes with elongated processes that bifurcate in different directions (arrows), unfused myosin stained cells (arrowheads), myotubes crossing the ventral midline (compare $\mathrm{d}$ and $\mathrm{f}$ ) and fusion of myotubes. ( $g$ and $\mathbf{h}$ ) Ventral regions of $s r$ mutant abdominal segments at stage 14 . Note that myotubes fail to extend filopodia (arrowhead), that they extend internally instead of extending towards the epidermis (myotybe below the arrowhead in g) and that they change tracks prior to their encounter with the epidermis (arrow). For further details see text.

the attachment cells (Figure 1a-d), the $s r$ mutant embryos show myotubes extending elongated membrane processes that often bifurcate in different directions (Figure le and f). In fully differentiated $s r$ mutant embryos, the myotubes were still not attached to the epidermis but instead are attached to other myotubes. Often the extended membrane processes of the myotubes cross the ventral midline (Figure 1f), a phenomenon which could never be observed in wild-type embryos (Figure $1 \mathrm{~b}$ and $\mathrm{d}$ ). These defects indicate that the myotubes of $s r$ mutant embryos are unable to form the stereotyped muscle pattern.

\section{Cloning and molecular characterization of the sr gene}

In order to understand the role of $s r$ in generating the somatic muscle pattern and to dissect its molecular function, we cloned the $s r$ gene. To facilitate the cloning, we searched for a P-element insertion that causes a $s r$ mutation. Surviving adults of the semi-lethal enhancer trap line l(3)03999 (Karpen and Spradling, 1992) show the adult $s r$ phenotype. The mutation generated by the l(3)03999 P-element insertion fails to complement the alleles $s r^{l}$ and $s r^{155}$ (data not shown).

Cloning of the $s r$ gene was initiated by plasmid rescue (Wilson et al., 1989) to isolate a DNA fragment flanking the P-element insertion (Figure 2a). This fragment was subsequently used to isolate overlapping genomic DNA fragments from a Drosophila $\lambda$-phage library covering some $50 \mathrm{~kb}$ of genomic DNA by chromosome walking and corresponding cDNAs (see Materials and methods). The structure of the $s r$ locus and the organization of two differentially spliced $s r$ transcripts, termed $s r$ a and $s r$ b, are summarized in Figure 2. The $l(3) 03999$ P-element insertion resides within the intron separating the different $5^{\prime}$ regions from the common $3^{\prime}$ region of the two transcripts (Figure 2a and b). Mobilization of the P-element (Bellen et al., 1989) restored $s r$ wild-type function due to the precise excision of the P-element (Figure 2c). This indicates that the P-element insertion is the cause of the $s r$ mutation. We also obtained embryonic lethal $s r$ alleles associated with P-element excisions which failed to complement the alleles $s r^{l}$ and $s r^{i 55}$ as well as the deficiency Df(3R)DG4. Of those, the allele $s r^{G l l}$ contains a $2074 \mathrm{bp}$ deletion of genomic DNA causing an embryonic lethal $s r$ allele (see Figure 2c).

We isolated five different cDNAs. They code for two alternatively spliced transcripts which share the two $3^{\prime}$ exons of the $s r$ gene (Figure $2 b$ ). The corresponding two protein variants have a common zinc finger DNA-binding domain containing a triple zinc finger motif (Figure 3a). This motif is diagnostic for the members of the egr-family of transcription factors of vertebrates (reviewed in Madden and Rauscher III, 1993). Of the known egr-type proteins, the triple zinc finger motif of human egr 1 protein (for a recent review see Gashler and Sukhatme, 1995) is most similar to the $s r$ proteins (Figure $3 b$ ). No sequence similarity has been found outside the triple zinc finger domain except for stretches of alanine and glutamine residues (Figure 3a) as commonly found in transcription factors (Courey and Tjian, 1988). The triple zinc finger motif and the nuclear localization of the $s r$ proteins (see below) suggest that the $s r$ gene encodes two variants of a transcription factor which act through the same DNA target sequence. Our analysis does not exclude the possibility of additional but minor $s r$ splicing variants.

\section{sr is expressed in ectodermal cells}

Expression of $s r$ was examined by in situ hybridization of transcript-specific probes from the $5^{\prime}$ untranslated regions of $s r$ a and $s r \mathrm{~b}$ respectively, or from the common exons of the two transcripts on whole mounted embryos at various stages of development. At stage 11, when myoblasts are formed from mesoderm internally, $s r$ expression occurs initially in a striped pattern and in small 


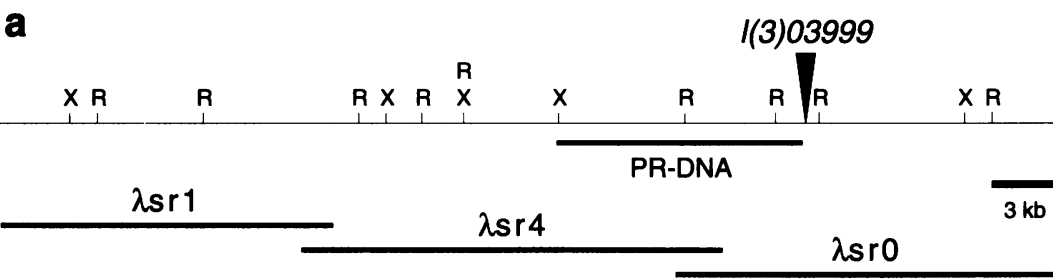

b

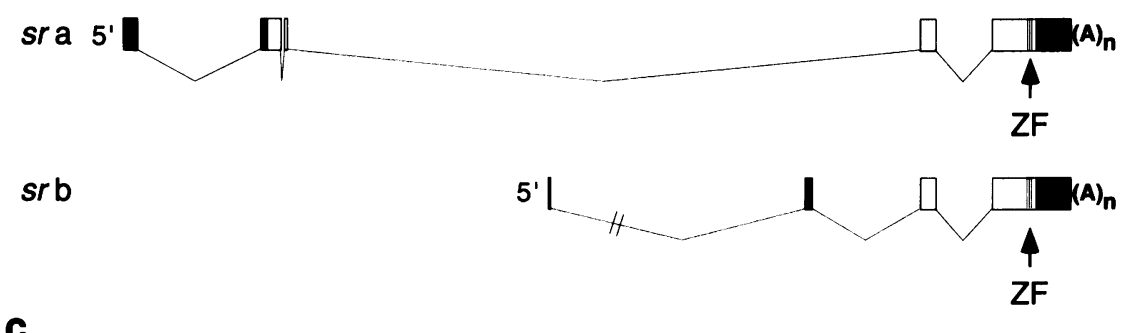

C

embryonic lethality $\quad$ or $r^{\mathrm{G} 11}$

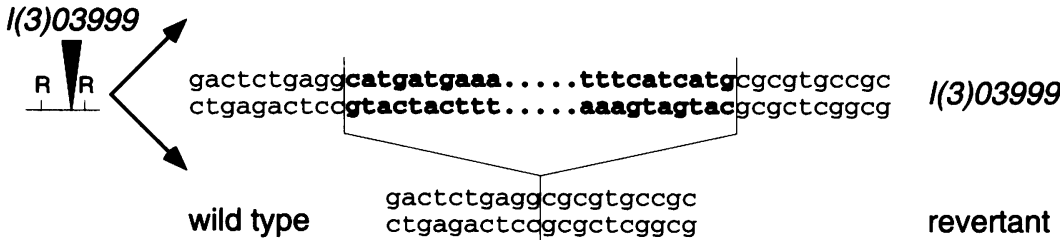

Fig. 2. Structure of the $s r$ gene and transcript organization. (a) Physical map of the $s r$ locus as established by recombinant $\lambda$-phage DNA isolated with the PR-DNA fragment obtained from a plasmid rescue of the P-element insertion site $l(3) 03999$ (arrowhead). Genomic phage clones $\lambda$ srl, $\lambda$ sr4, $\lambda s r 0$ represent the minimal overlap DNA covering the $s r$ locus. R: EcoRI; X: XbaI. The l(3)03999 P-element insertion is located within the cytogenetic interval 90E1,2 at the right arm of the third chromosome (Berkeley Drosophila Genome Project; own observation) and causes an $s r$ mutation (see text). (b) Genomic organization of the two differentially spliced $s r$ transcripts ( $s r$ a and $s r$ b). Exon/intron boundaries were established by sequencing cDNA and the corresponding genomic DNA (a). Filled bars: untranslated sequences; open bars: coding region; vertical lines: zinc finger motifs (ZF); (A) $)_{n}$ : poly(A) track. (c) The $l(3) 03999$ insertion (middle row) causes an adult $s r$ mutant phenotype. Note that the reversion to wild-type is due to a precise excision of the P-element ('revertant'; bottom row) while an imprecise excision associated with a 2074 bp deletion $\left(s r^{G l l}\right.$; stippled bar in top row) causes embryonic lethality (see Materials and methods).

clusters of segmentally arranged ectodermal cells (Figure 4a). At subsequent stages, when the myotubes stretch and enlarge by continuous fusion with myoblasts, $s r$ expression persists exclusively in the epidermal cells to which the myotubes eventually become attached (Figure $4 b, c$, f and g). $s r$ b transcripts are found in all muscle attachment cells (Figure $4 \mathrm{~d}$ and $\mathrm{h}$ ), whereas the $s r$ a transcripts appear later in development and are restricted to a subset of these cells (Figure $4 \mathrm{e}$ and i). These results suggest that $s r$ expression is confined exclusively to ectodermal cells and epidermal derivatives which serve as the muscle attachment cells.

In order to establish the ectodermal restriction of $s r$ expression unambiguously, we generated antibodies directed against the protein region common to both proteins (see Materials and methods). Antibody staining of whole mount preparations of embryos revealed that the $s r$ proteins are expressed exclusively in the nuclei of ectodermal and epidermal cells (Figure 5), i.e. neither $s r$ transcripts nor $s r$ protein was found in muscles or muscle precursors.

\section{sr mutations affect muscle attachment cells and myotube guidance}

Since the nuclear location of the $s r$ proteins and the conserved zinc finger DNA-binding consistently argue that $s r$ encodes a cell-autonomous transcription regulator, we next asked whether the $s r$-expressing muscle attachment cells develop abnormally. For this we examined the expression of a set of known differentiation markers. As compared with wild-type (Figure 6a,c and e), the number of epidermal cells expressing the muscle attachment markers groovin (Volk and VijayRaghavan, 1994), delilah (Armand et al., 1994) and B1-tubulin (Buttgereit et al., 1991) is greatly reduced and their normally stereotyped expression patterns are strongly disturbed in $s r$ mutants (Figure 6b,d and f) without affecting the normal cuticular pattern of the larvae (data not shown). We note that the reduction of attachment cell marker gene expression and their patterns were also observed in embryos which lack $s r$ function due to a chromosomal deficiency (results not shown). This suggests some redundancy in the factors regulating the expression of groovin, delilah and $\beta 1$ tubulin. Taken together, these findings are consistent with the proposal that the abnormal muscle pattern of $s r$ mutants results from a defective function of the muscle-attachment cells to guide the myotubes to their proper sites. In order to test this proposal, we examined the development of the muscle pattern from early stage onwards.

The early steps of myogenesis such as myotube formation, the initial arrangement of muscle precursors and the 
MLLTMRRQNE LIVGSQQHPS ATSSASSSAG ATSSPGLSGQ NLNLVAGAGA ATNSTSANSQ DSLNTPTTPL LGLSRNPLQF APPPAPPIAV PSPAASGPTF GYYQTANAAP PLHHSPAATS EVSTAPQPPV ELDEYVDILQ VQQLLLDSSA AAAAAANNPP TTEQSVQQPQ QNTVVQPHPH QQQQQPQQQQ QQPQQVLAKP RPRINLQKAT EYAAQLAQVE SSSPGSRRVL LDYPSPYLYG NPYHHHTPPG EDLVALWFGS NGTGGVAPGT PSAAMIMEGL ETLVAPTHHA FLLTETAAAA HFNVLSFDTC LFKTSTAAQS SGSPSTATYL SPAOFGGSHH GGASTSSNSL NSSSTASSSS TSSSLLHYTT ASAAAAAAAA AAASANNSVL RARNOTATPT OGGSPGHVAV OPSATASSGR SSASHLSLLN TSGQHSPTSS AVEQVEAHKQ LIEALPGDLN TPVTTSSDIP SFFGPTTVVE PPPITGSIES EDLSLEPQVI SVASPVLSHC SPLKEERSTP PALAIVKEES SNNSCNMYPQ HNNNNNNNNN TTSSSTTTTS KQTTSESNTE CVGSPGNHTQ SHQQQQQQLQ HNNTSSSNSN CHHSHQQQQQ QQQQQHMSSP QQQYQQHQIL HQQQQFGYHH HHHHHHHHH SQLQQLQQQQ QQOQOOOOHQ QQPLHQQQQL QHQQQQQHHQ QHYQQHAIQH QQSQQQASKI SYRGIFTTTG NAMNAAAAAA AAAAQQQHQQ QQQHQQQLPS PQLGVLAGPM SPPSNSLGNS WGLPSPDKTM FQPPLFSLPA HYATMQQQQQ QQQQQQQQQQ QQQAAGAAPS PYDDGRAAAA AAAQHAELLG LTMDCTPLLL KQPPPSYAGA SAGFPGLGDL HSSHEQQLQQ QQYVRSQPKY QWLDSPADYA QQQQQVQQVQ QQQQQQQTLV LPGPTSSASS SNAALGVLIP KQENYPDMQP SSNGTGYSGG SGGSSAAAAA AAAAAAAAVQ LAEYSPSTSK GHEILSQVYQ QSTVPLKLVP VKPRKYPNRP SKTPVHERPY ACPVENCDRR FSRSDELTRH IRIHTGQKPF QCRICMRSFS RSDHLTTHIR THTGEKPFSC DICGRKFARS DEKKRHAKVH LKQRIKKEKV RGEQQQQQQQ QQQQQQQQQQ QQLQQQQEQH HLSLQQHQQY QQHHLLHSAD LAIVTSSASM

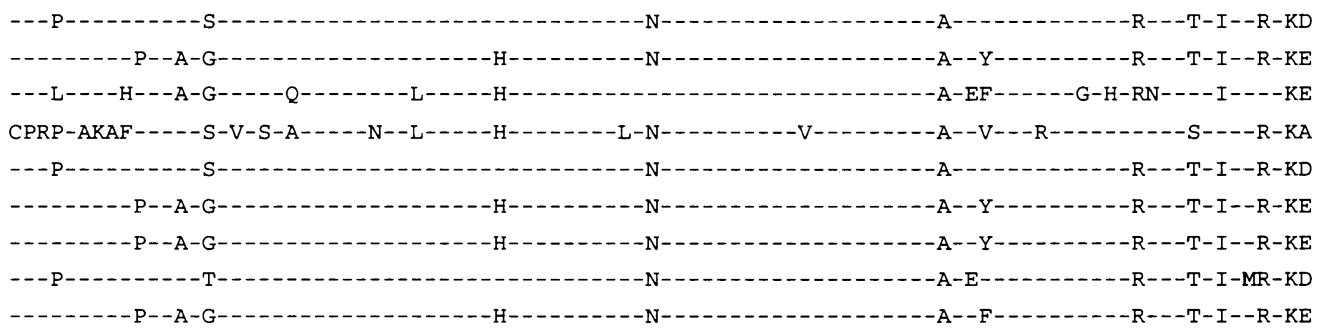

$\begin{array}{lll}\text { EGR1 } & \text { human } & 89 \% \\ \text { EGR2 } & \text { human } & 86 \% \\ \text { EGR3 } & \text { human } & 82 \% \\ \text { EGR4 } & \text { human } & 73 \% \\ \text { EGR1 } & \text { mouse } & 89 \% \\ \text { EGR2 } & \text { mouse } & 86 \% \\ \text { EGR2 } & \text { Xenopus } & 86 \% \\ \text { EGR1 } & \text { zebrafish } & 87 \% \\ \text { EGR2 } & \text { zebrafish } & 86 \%\end{array}$

Fig. 3. stripe encodes two protein variants containing a common egr-like triple zinc finger domain. (a) Protein sequences encoded by the 3540 bp open reading frame of the $s r$ a transcript (giving rise to a 1180 amino acid protein starting with Met in position 1; arrow) and by the 2718 bp open reading frame of the $s r$ b transcript (giving rise to a 906 amino acid protein starting with Met in position 275; arrow). Note that the $s r$ b protein is fully contained within the $s r$ a protein due to alternative splicing as shown in Figure $2 \mathrm{~b}$ and that the predicted open reading frames of $s r$ a and $s r \mathrm{~b}$ begin with a consensus Drosophila translation initiation sequence (Cavener and Ray, 1991). The zinc finger motifs of the $s r$ a and $s r$ b proteins are underlined. The nucleotide sequences of the transcripts $s r$ a and $s r$ b are available in the EMBL gene bank under accession numbers U42402 and U42403. (b) Sequence comparison of the triple zinc finger domain common to $s r$ a and $s r$ b proteins ( $\mathrm{Sr}$ ) with known members of the egr zinc finger family of transcription factors (Chavrier et al., 1988; Christy et al., 1988; Joseph et al., 1988; Sukhatme et al., 1988; Suggs et al., 1990; Muller et al.. 1991: Patwardhan et al.. 1991; Bradley et al., 1993; Madden and Rauscher III, 1993; Oxtoby and Jowett, 1993; Drummond et al., 1994). Boxes frame the cysteine and histidine residues coordinating the putative $\mathrm{Zn}^{2+}$ binding of the underlined finger motifs 1-3 (finger 1, 2, 3). Identical amino acid residues are indicated by dashes; \% refers to sequence identity in the zinc finger domain of egr proteins (EGR) from vertebrate species relative to the $s r$ protein of Drosophila. No significant sequence homology outside the zinc finger domain was detected (Altschul et al., 1990).

expression of cellular marker genes such as nautilus (Michelson et al., 1990), D-mef2 (Lilly et al., 1994; Nguyen et al., 1994) and myosin (Kiehart and Feghali, 1986) are normal in $s r$ mutant embryos (data not shown). At later stages, however, $s r$ mutant embryos show a large number of unfused cells expressing the muscle-specific myosin heavy chain (examples marked with arrowheads in Figure 1e and $\mathrm{f}$ ). Thus, a substantial portion of the myoblasts must have failed to fuse during myotube extension, but they continue myogenesis as implicated by their expression of the muscle cell-specific gene.

From early stage 14 onwards, $s r$ mutant myotubes change their normally stereotyped routes in an erratic manner. Examples outlined in Figure $1 \mathrm{~g}$ and $\mathrm{h}$ indicate that the $s r$ mutant myotubes fail to extend filopodia or their filopodia extend internally instead of following their normal tracks along the inner surface of the epidermis. Also, $s r$ mutant myotubes often exert elongated processes in different directions (Figure $1 \mathrm{~g}$ and $\mathrm{h}$ ). These findings suggest that $s r$ is a key gene in the differentiation of the muscle attachment cells which is responsible for their ability to provide guiding cues for the migration of myotubes towards the epidermal targets.

\section{Discussion}

We present evidence that the formation of the larval muscle pattern in the Drosophila embryo depends on the activity of an epidermally expressed zinc finger protein. The nuclear location of the $s r$ proteins and their high degree of sequence conservation within the conserved triple zinc finger motif allows them to be grouped as a member of the egr-family of transcription factors known from vertebrates (reviewed in Madden and Rauscher III, 1993; Pieler and Bellefroid, 1994; Gashler and Sukhatme, 1995). Since transcription factors act in a cell-autonomous manner and $s r$ is not expressed in muscles and/or muscle precursors, our results also provide evidence that the establishment of the muscle pattern in Drosophila requires the interaction between muscles and epidermal cells.

The possibility that the formation of the stereotyped muscle pattern in insects depends on an interaction between the two different germ layer derivatives is based on experiments involving rotated epidermal transplants with the beetle Tenebrio molitor (Williams and Caveney, 1980a,b), reassociation of myotubes and ectodermal cells in Drosophila embryo culture (Volk and VijayRaghavan, 

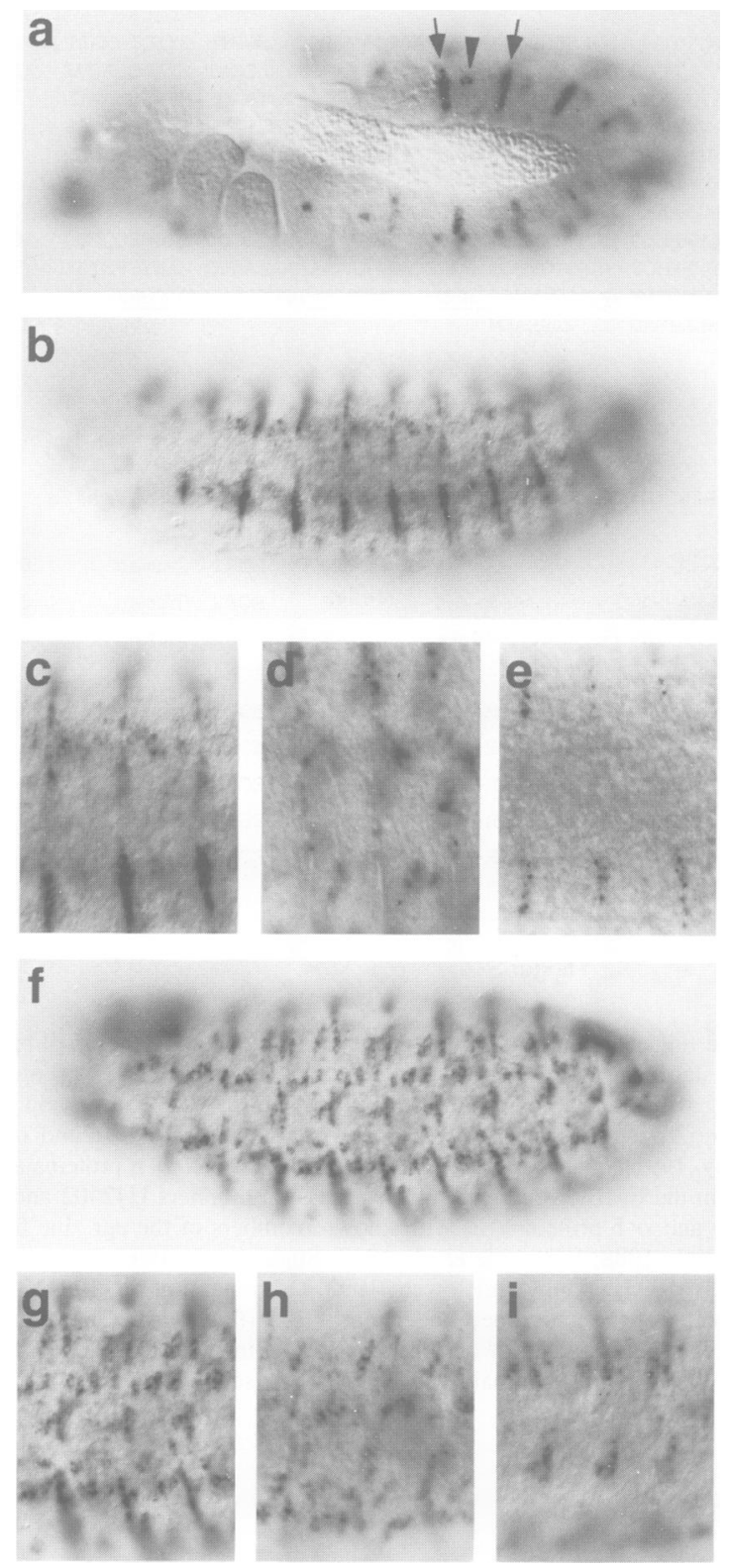

Fig. 4. $s r$ expression patterns revealed by in situ hybridization of whole mount Drosophila embryos. A probe common to $s r$ a and $s r$ b $(\mathbf{a}-\mathbf{c}, \mathbf{f}$ and $\mathbf{g})$ or specific probes for $s r$ a (e and $\mathbf{i})$ or $s r \mathbf{b}$ (d and $\mathbf{h}$ ) were used to show the initial $s r$ expression in ectodermal cells of embryos at stage 11 (a), stage 13 (b-e) and stage 16 (f-i); stages according to Campos-Ortega and Hartenstein (1985). Note rows of epidermal cells at the segmental boundaries (arrows in a) and clusters of intrasegmental cells (arrowheads in a) at stage 11. Since the same pattern was observed with the $s r$ b-specific probe, but no transcripts were found with the $s r$ a-specific probe (data not shown), the initial $s r$ expression involves the $s r$ b transcript exclusively. (b) Lateral overview of $s r$ expression in the developing epidermis of stage 13 embryos. (c-e) Enlarged lateral epidermal regions of stage 13 embryos showing the same expression pattern with the common probe (c). Note differences in the pattern obtained with the $s r$ b-specific probe (d), and the restriction of $s r$ a expression along the segmental furrows (e).

(f) Lateral overview of $s r$ expression in the epidermis of a stage 16 embryo. (g-i) Enlarged lateral epidermal regions of stage 16 embryos showing that the expression pattern with the common probe $(\mathrm{g})$ is also observed in different intensities with the $s r$ b-specific probe $(\mathrm{h})$, while $s r$ a expression is restricted to a subset of these cells (i). For a detailed description of the pattern of muscle attachment cells see Armand et al. (1994).
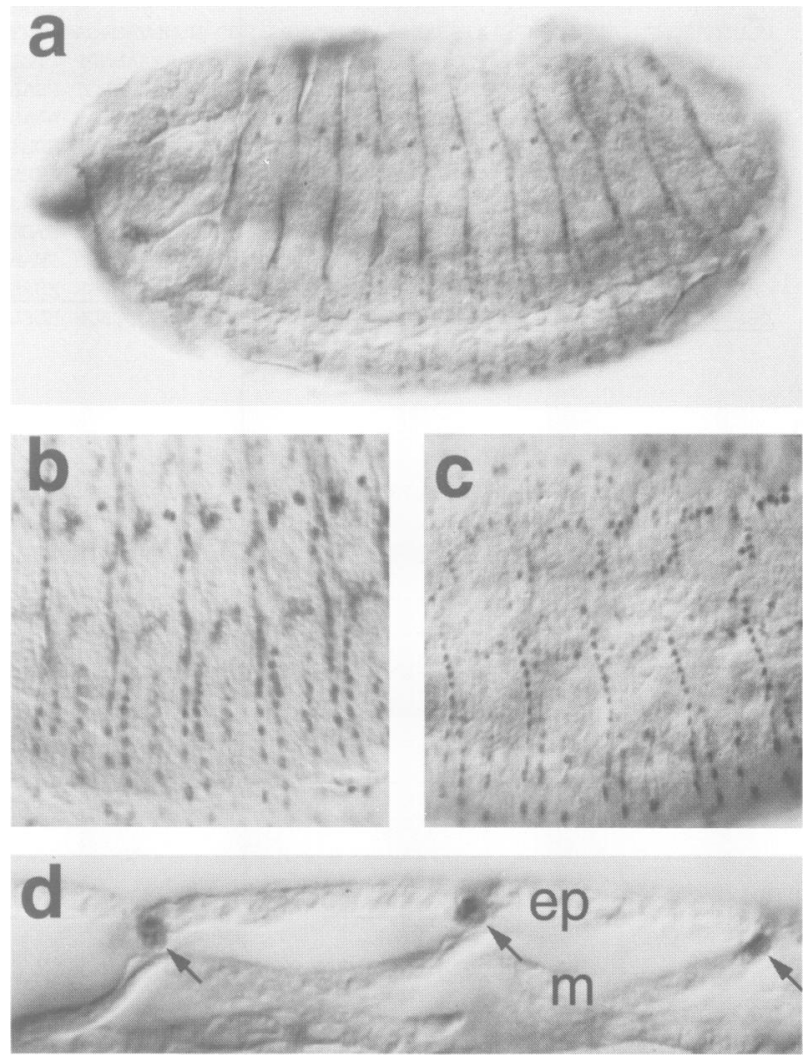

Fig. 5. $s r$ protein expression in muscle attachment cells of wild-type embryos. (a) Whole mount preparation of a stage 13 embryo. Note the nuclear expression as revealed by antibodies directed against both $s r$ proteins (see Materials and methods). (b) Enlarged lateral epidermal region of a stage 14 embryo. (c) Corresponding region of a stage 16 embryo. Orientation of embryos in a-c is anterior left, dorsal up. (d) Optical longitudinal section in a ventral position of a stage 16 embryo (anterior left; right side up). Note that the antibody staining (arrow) is restricted to the nuclei of epidermal muscle attachment cells (ep: epidermis; m: approaching muscle).

1994) and the notion of defects in the muscle pattern in various segment polarity mutants (Volk and VijayRaghavan, 1994). The findings that $s r$ mutant myotubes fail to attach to epidermal cells and that epidermal $s r$ activity is necessary for the directed growth of myotubes suggest that $s r$ participates in two processes, myotube guidance and muscle attachment. Both functions are consistent with a function of $s r$ in the ectodermal cells that gives rise to the muscle attachment cells, implying a cross-talk between myotubes and epidermal cells responsible for generating the muscle pattern during embryogenesis.

Muscle attachment appears to involve the expression of cell-surface receptors, such as the position-specific integrins, in both the myotube and the epidermis. Mutations of individual integrin subunits, which are expressed in complementary patterns in the cell membranes of the epidermis and the muscle fibers, do not interfere with the formation of wild-type pattern of somatic musculature but rather cause the detachment as contraction occurs (Bogaert et al., 1987; Brown, 1994; Brower et al., 1995). In the most severe integrin mutation myospheroid, the final muscle pattern observed at stage 16 is normal. The difference between the $s r$ phenotype and the one caused 


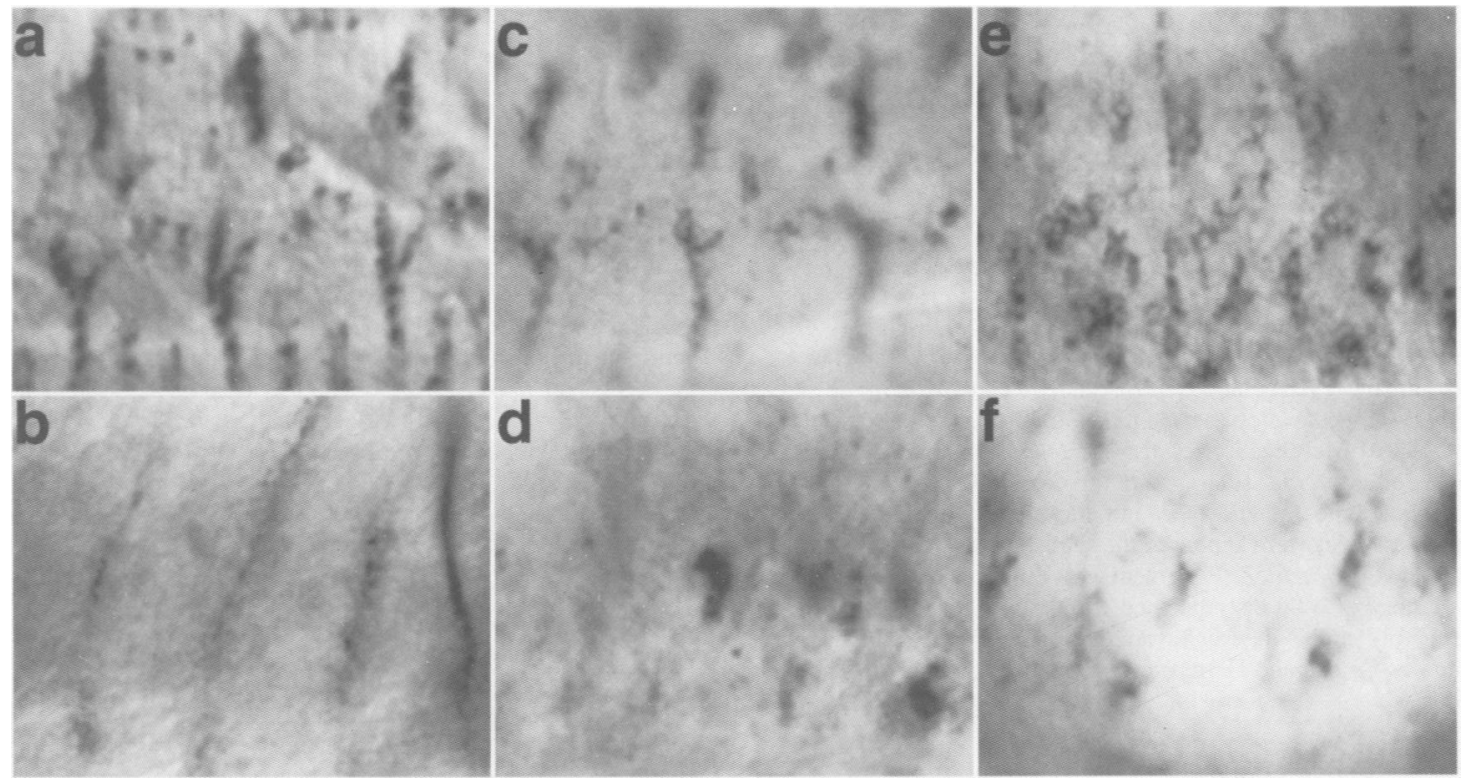

Fig. 6. Expression of muscle attachment cell-specific markers in wild-type (a, $\mathbf{c}$ and $\mathbf{e})$ and corresponding epidermal regions of the $s r$ mutant (b, $\mathbf{d}$ and $\mathbf{f}$ ) embryos as visualized by whole-mount in situ hybridization. Note the differences in the expression patterns of groovin (Volk and VijayRaghavan, 1994) (a and b), delilah (Armand et al., 1994) (c and d) and B1-tubulin (Buttgereit et al., 1991) (e and f) with respect to the number and patterns of expressing cells indicating that the normal differentiation of muscle attachment cells is impaired. Orientation of embryos is anterior left and dorsal to the top; for a detailed view of the attachment cell pattern see Figure 4.

by integrin mutations suggests that $s r$ acts at a different cellular level. $s r$ already interferes with the recognition of the attachment cells by the myotubes or vice versa, while the integrins, and possibly a number of additional factors such as $\beta 1$-tubulin (Buttgereit et al., 1991) and tiggrin (Fogerty et al., 1994), are required to establish adherencetype junctions to withstand the tensile forces of muscle contraction once the myotube-epidermis connection is made.

In addition to myotubes not attaching to the epidermis, we have noted expression of the muscle-specific myosin heavy chain in a large number of single cells or cell clusters, indicating that not all myoblasts have been fused with the migrating myotubes. They continue myogenesis as individual cells, probably guided by a cell-autonomous program. Laser ablation studies in grasshopper reveal distinct muscle pioneers (Ball et al., 1985). In Drosophila, binucleate and trinucleate cells of mesodermal origin were found at corresponding positions. Bate (1990) inferred from these observations that muscle patterning is based on a single 'founder cell' for each muscle fiber and that the intermediate myotube collects a muscle-specific number of 'fusion-competent cells' when extending. Muscle fiber diversification might therefore be specified by information contained within the founder cells and transferred to the unspecified fusion-competent cells as they fuse with the enlarging myotubes (reviewed in Abmayr et al., 1995). In $s r$ mutant embryos, myotubes are detoured and form bifurcated cellular processes which grow in different directions and thereby alter their normal tracks. Taken together, these observations indicate that the ectoderm must provide positional information which attracts or orients the migrating myotube before it serves as a muscle-attachment cell. In view of the myosin heavy chain expressing single cells and unfused cell clusters, one can envision a scenario where, due to the misrouting of the myotubes, some fusion-competent myoblasts along the normal track are left aside and therefore undergo myogenesis in a cell-autonomous manner.

The notion of growth-cone-like structures at the leading edges of the myotubes (Bate, 1990), their directed growth towards their epidermal targets (Bate, 1990, 1993) and the finding that the latter process requires $s r$-dependent information coming from a distinct set of epidermal cells, is reminiscent of the process of axonal pathfinding during neurogenesis including synaptic targeting (reviewed in Goodman and Doe, 1993). We therefore assume that the $s r$-expressing epidermal cells may serve as a source of signals that act over a distance to be sensed by the growthcone-like processes of the migrating myotubes. The $s r$ expressing cells may also or exclusively represent distinct guide-post cells, providing distinct molecular labels which are recognized by the leading edges of the myotubes. Since $s r$ encodes a nuclear protein likely to act as a transcriptional regulator, it is obvious that $s r$ can provide this function only indirectly.

We propose that $s r$ is required for the early and late differentiation of the muscle attachment cells. Alternatively or in addition, $s r$ may be essential for specific cellular aspects of attachment cell function by acting on top of a genetic circuitry that provides signaling and/or cell-surface molecules to be specifically recognized by the myotubes. Our data do not allow for distinction between these possibilities, since target genes of $s r$ and the molecular nature of their products are not yet identified. Given the limited knowledge of the molecules and the mechanisms underlying cell guidance over distance and cell recognition, and the emerging conservation of myogenic processes throughout the animal kingdom (Donoghue and Sanes, 1994; Olson and Rosenthal, 1994), our findings provide an entry point into the functional interplay between ectodermal and mesodermal derivatives. This interplay 
involves the generation of one or several ectodermal signals, their reception and the integration of their information by myotubes.

\section{Materials and methods}

Fly stocks, P-element reversion and embryo collection Fly stocks were kept as described (Roberts, 1986). The following strains were used: Oregon $\mathrm{R}$ wild-type flies, $s r^{l}$ (Bridges and Morgan, 1923), deficiency Df(3)DG4 (Lindsley and Zimm, 1992), $s r^{155}$ (De La Pompa et al., 1989) and the P-element insertion line l(3)03999 (Karpen and Spradling, 1992) which develop the $s r$ mutant adult phenotype (Costello and Wyman, 1986). Mobilization of the P-element was performed as described by (Bellen et al., 1989), resulting in a reversion of the $s r$ mutant adult phenotype to wild-type and the embryonic lethal $s r^{G / l}$ allele. The mutant alleles were kept over the 'blue balancer chromosome' TM3 with a $h b$ - or ftz-lacZ P-element to allow the genotype of homozygous embryos to be distinguished from heterozygous and wildtype siblings (Volk and VijayRaghavan, 1994). Collection of staged embryos (Campos-Ortega and Hartenstein, 1985) was done as described (Roberts, 1986).

\section{Cloning and sequence analysis}

The recombinant DNA techniques were done according to Sambrook et al. (1989). Cloning of the $s r$ gene was initiated with insertion site associated genomic Drosophila DNA obtained by plasmid rescue (Wilson et al., 1989) followed by chromosome walking (Sambrook et al., 1989) using the plasmid rescued DNA (PR-DNA; see Figure $2 a$ ) as a starting point to isolate recombinant $\lambda$-phages by screening a genomic Drosophila DNA library (Stratagene). cDNA clones were isolated by screening cDNA libraries prepared from polyA(+) RNA of 0-18 h (ITC) and 2$14 \mathrm{~h}$ (Stratagene) old embryos. DNA fragments isolated from phages or cDNA clones were subcloned into Bluescript vectors (Stratagene). A total of five different cDNAs were analysed. The cDNA sequences and sequences of the corresponding genomic DNA, including flanking sequences, sequences surrounding the P-element insertion site and the $s r^{G l l}$ deletion, were determined on both strands using the dideoxynucleotide method (Sanger et al., 1977) employing automated sequencing. Sequence comparison to databases was performed by use of the HUSAR software package (Devereux et al., 1984).

\section{Molecular characterization of sr alleles}

Mobilization of the single P-element (Bellen et al., 1989) of the l(3)03999 line resulted in wild-type revertants and the embryonic lethal $s r^{G / l}$ allele. The precise excision of the P-element in wild-type revertant stocks was established by Southern blot analysis involving the DNA fragment containing the insertion site (see Figure $2 \mathrm{a}$ ) and by sequencing DNA across the PCR-amplified (Saiki et al., 1988) integration point (see below). The deletion associated with the $s r^{G l l}$ allele was identified by Southern blot analysis and by sequencing of the DNA at the borders of the deletion obtained by PCR-amplification. These analyses were carried out with genomic DNA prepared from $\sim 20$ homozygous embryos (identified on the basis of the 'blue balancer chromosome'; see above) or from one fly (identified as homozygous $s r$ mutant on the basis of the adult phenotype). From these DNAs, a DNA fragment encompassing the P-element insertion point was amplified by the polymerase chain reaction using the deoxyoligonucleotides 5 '-CATCCATAAGCTTAAACTGTG- $3^{\prime}$ and $5^{\prime}$-TCGTAGGATATGTATGTTACA- ${ }^{\prime}$ as primers for the $s r^{G l l}$ deletion and 5'-TCGAGACATATGACGTCGATG-3' and 5'CACAACTGAGGCACGAGATGC-3' as primers for both wild-type and revertant DNA. The PCR-amplified DNAs were cloned into Bluescript vectors and sequenced following the procedures described above.

\section{Production of polyclonal antibodies directed against sr protein}

A NheI-Xhol genomic fragment encoding the amino acid interval $707-$ 1180 of the common part of the putative $s r$ a and $s r$ b proteins was cloned into the expression vector pRSET (Invitrogen) allowing for the production of a histidine-tagged fusion protein in Escherichia coli BL21(DE3) (Studier and Moffat, 1986). The resulting recombinant protein with the apparent molecular weight of $64 \mathrm{kDa}$ was purified on ProBond ${ }^{\mathrm{TM}}$ Resin (Invitrogen) according to the manufacturer's protocol, separated from possible contaminants by SDS-PAGE (Sambrook et al., 1989) and used for immunization of rabbits at Eurogentec (Brussels).
The serum was pre-absorbed by an overnight incubation with fixed devitellinized embryos as described (Roberts, 1986).

\section{Analysis of expression patterns}

Staged (Campos-Ortega and Hartenstein, 1985) wild-type and transheterozygous $s r^{155} / \mathrm{Df}(3 \mathrm{R}) \mathrm{DG} 4$ embryos were fixed either for in situ hybridization (Tautz and Pfeifle, 1989) or antibody staining (Macdonald et al., 1986). In situ hybridization of fixed whole mounted embryos was performed as described (Tautz and Pfeifle, 1989) using either digoxigeninlabeled DNA probes derived from the transcript-specific $5^{\prime}$ regions of the $s r$ a and the $s r$ b cDNAs respectively, or from the $3^{\prime}$ cDNA region common to both transcripts. Antibody stainings were performed using the Vectastain $\mathrm{ABC}$ Elite horseradish peroxidase system according to the protocol as described (Macdonald et al., 1986). The anti-myosin heavy chain antibodies were obtained from P.Fisher (New York).

\section{Acknowledgements}

We thank our colleagues in the laboratory, D.Wilkinson, A.Ferrús, A.Spradling, M.Cole, D.Kiehart, M.Bate, A.Michelson, D.Buttgereit, for their various important contributions and G.Dowe for sequencing and oligonucleotide synthesis. This work was supported by the Max-Planck Society, the Sonderforschungsbereich 271 of the Deutsche Forschungsgemeinschaft (H.J.), grants from the German-Israeli Foundation, and the Forchheimer Center (T.V.). G.V. received a fellowship of the Deutsche Forschungsgemeinschaft.

\section{References}

Abmayr,S.A., Erickson,M.S. and Bour,B.A. (1995) Embryonic development of the larval body wall musculature of Drosophila melanogaster. Trends Genet., 11, 153-159.

Altschul,S.F., Gish,W., Miller,W., Myers,E.W. and Lipman,D.J. (1990) Basic local alignment search tool. J. Mol. Biol., 215, 403-410.

Armand,P., Knapp,A.C., Hirsch,A.J., Wieschaus,E.F. and Cole,M.C. (1994) A novel basic helix-loop-helix protein is expressed in muscle attachment sites of the Drosophila epidermis. Mol. Cell. Biol., 14, $4145-4154$.

Ball,E.E., Ho,R.K. and Goodman,C.S. (1985) Muscle development in the grasshopper embryo. I Muscles, nerves and apodemes in the metathoracic leg. Dev. Biol., 111, 383-398.

Bate,M. (1990) The embryonic development of larval muscles in Drosophila. Development, 110, 791-804.

Bate,M. (1993) The mesoderm and its derivatives. In Bate,M. and Martinez Arias,A. (eds), The Development of Drosophila melanogaster. Cold Spring Harbor Laboratory Press, Cold Spring Harbor, NY, pp. 1013-1090.

Bellen,H.J., O'Kane,C.J., Wilson,C., Grossniklaus,U., Pearson,R.K. and Gehring,W.J. (1989) P-element-mediated enhancer detection, a versatile method to study development in Drosophila. Genes Dev., 3 , $1288-1300$

Bogaert,T., Brown,N. and Wilcox,M. (1987) The Drosophila PS2 antigen is an invertebrate integrin that, like the fibronectin receptor, becomes localized to muscle attachments. Cell, 51, 929-940.

Bradley,L.C., Snape,A., Bhatt,S. and Wilkinson,D.G. (1993) The structure and expression of the Xenopus Krox-20 gene, conserved and divergent patterns of expression in rhombomeres and neural crest. Mech. Dev., 40, 73-84.

Bridges,C.B. and Morgan,T.H. (1923) The third-chromosome group of mutant characters of Drosophila melanogaster. Publications of the Carnegie Institution, 327, 1-251.

Brower,D.L. et al. (1995) Nonequivalent requirements for PS1 and PS2 integrin at cell attachments in Drosophila, genetic analysis of the alpha PS1 integrin subunit. Development, 121, 1311-1320.

Brown,N.H. (1994) Null mutations in the $\alpha$ PS2 and $\beta$ PS integrin subunit genes have distinct phenotypes. Development, 120, 1221-1231.

Buttgereit,D., Leiss,D., Michiels,F. and Renkawitz-Pohl,R. (1991) During Drosophila embryogenesis the $\beta 1$ tubulin gene is specifically expressed in the nervous system and the apodemes. Mech. Dev., 33, 107-118.

Campos-Ortega,J.A. and Hartenstein,V. (1985) The Embryonic Development of Drosophila melanogaster. Springer, Berlin, Germany.

Cavener,D.R. and Ray,S.C. (1991) Eukaryotic start and stop translation sites. Nucleic Acids Res., 19, 3185-3192.

Chavrier,P., Zerial,M., Lemaire,P., Almendral,J., Bravo,R. and Charnay,P. (1988) A gene encoding a protein with zinc fingers is activated during G0/G1 transition in cultured cells. EMBO J., 7, 29-35. 
Christy.B.A., Lau,F.L. and Nathans,D. (1988) A gene activated in mouse $3 \mathrm{~T} 3$ cells by serum growth factors encodes a protein with 'zinc finger" sequences. Proc. Natl Acad Sci. USA, 85, 7857-7861.

Costello,W.J. and Wyman,R.J. (1986) Development of an indirect flight muscle in a muscle-specific mutant of Drosophila melanogaster. Dev Biol., 118. 247-258.

Courey,A.J. and Tjian,R. (1988) Analysis of Spl in vivo reveals multiple transcriptional domains, including a novel glutamine-rich activation motif. Cell, 55, 887-98.

De La Pompa.J.L., Garcia.J.R. and Ferrús.A. (1989) Genetic analysis of muscle development in Drosophila melanogaster. Dev: Biol., 131. 439-454.

Devereux,J., Haeberli,P. and Smithies,O. (1984) A comprehensive set of sequence analysis programs for the VAX. Nucleic Acids Res., 12. 387-395.

Donoghue.M.J. and Sanes.J.R. (1994) All muscles are not created equal. Trends Genet., 10, 396-401.

Drummond,I.A., Rohwer,N.P. and Sukhatme.V.P. (1994) The zebrafish egrl gene encodes a highly conserved, zinc-finger transcriptional regulator. DNA Cell Biol., 13, 953-961.

Fogerty,F.J. et al. (1994) Tiggrin, a novel Drosophila extracellular matrix protein that functions as a ligand for Drosophila $\alpha$ PS2 $\beta$ PS integrins. Development, 120, 1747-1758.

Frasch.M. (1995) Induction of visceral and cardiac mesoderm by ectodermal $d p p$ in the early Drosophila embryo. Nature, 374, 464-467.

Gashler,A. and Sukhatme.V.P. (1995) Early growth response protein 1 (Egr-1), prototype of a zinc-finger family of transcription factors. In Cohn,W.E. and Moldave,K. (eds), Progress in Nucleic Acid Research and Molecular Biology: Academic Press, San Diego, CA, pp. 191-224.

Goodman.C.S. and Doe,C.Q. (1993) Embryonic development of the Drosophila central nervous system. In Bate.M. and Martinez Arias.A (eds), The Development of Drosophila melanogaster. Cold Spring Harbor Laboratory Press, Cold Spring Harbor, NY, pp. 1131-1206.

Joseph,L.J.. Le,B.M., Jamieson,G.J., Acharya,S., Shows,T.B., Rowley, J.D. and Sukhatme,V.P. (1988) Molecular cloning, sequencing, and mapping of EGR2, a human early growth response gene encoding a protein with zinc-binding finger structure. Proc. Natl Acad. Sci. USA, 85, 7164-7168.

Karpen,G.H. and Spradling,A.C. (1992) Analysis of subtelomeric heterochromatin in the Drosophila minichromosome Dp1187 by single P element insertional mutagenesis. Genetics, 132, 737-753.

Kiehart,D.P. and Feghali.R. (1986) Cytoplasmic Myosin from Drosophila melanogaster. J. Cell Biol., 103, 1517-1525.

Lilly,B., Galewsky,S., Firullu,A.B., Schulz,R. and Olson,E.N. (1994) DMEF2, A MADS box transcription factor expressed in differentiating mesoderm and muscle cell lineages during Drosophila embryogenesis. Proc. Natl Acad. Sci. USA, 91, 5662-5666.

Lindsley.D.L. and Zimm,G.G. (1992) The Genome of Drosophila melanogaster. Academic Press, San Diego, CA.

Macdonald,P.M., Ingham,P.W. and Struhl,G. (1986) Isolation, structure, and expression of even skipped: a second pair-rule gene of Drosophila containing a homeobox. Cell, 47, 721-734.

Madden,S.M. and Rauscher III,F.J. (1993) Positive and negative regulation of transcription and cell growth mediated by the EGR family of zinc-finger gene products. In Sluyser,M., Ab,G.. Brinkmann,A.O. and Blankenstein.R.A. (eds), Zinc-finger Proteins in Oncogenesis: DNA-binding and Gene Regulation. The New York Academy of Sciences, New York, pp. 75-84.

Michelson,A.M., Abmayr,S., Bate,M., Martinez Ariaz,A. and Maniatis,T. (1990) Expression of a MyoD family member prefigures muscle pattern in Drosophila embryos. Genes Dev., 4, 2086-2097.

Muller.H.J.. Skerka,C., Bialonski,A. and Zipfel,P.F. (1991) Clone pAT 133 identifies a gene that encodes another human member of a class of growth factor-induced genes with almost identical zinc-finger domains. Proc. Natl Acad. Sci. USA, 88, 10079-10083.

Nguyen,H.T., Bodmer,R., Abmayr,S.M., McDermott,J.C. and Spoerel,N.A. (1994) D-mef2: a Drosophila mesoderm-specific MADS box-containing gene with a biphasic expression profile during embryogenesis. Proc. Natl Acad. Sci. USA, 91, 7520-7524.

Olson.E.N. and Rosenthal.N. (1994) Homeobox genes and muscle patterning. Cell, 79, 9-12.

Oxtoby.E. and Jowett.T. (1993) Cloning of the zebrafish krox-20 gene ( $\mathrm{krx}-20)$ and its expression during hindbrain development. Nucleic Acids Res., 21, 1087-1095.

Patwardhan.S., Gashler.A.. Siegel.M.G., Chang.L.C., Joseph.L.J., Shows.T.B.. Lebeau.M.M. and Sukhatme.V.P. (1991) EGR3, a novel member of the Egr family of genes encoding immediate-early transcription factors. Oncogene, 6. 917-928.

Pieler,T. and Bellefroid,E. (1994) Perspectives on zinc finger protein function and evolution - an update. Mol. Biol. Reports, 20, 1-8.

Roberts,D.B. (1986) Basic Drosophila care and techniques. In Roberts,D.B. (ed.), Drosophila, a Practical Approach. IRL Press, Oxford, UK, pp. 1-39.

Saiki,R.K., Gelfand.D.H., Stoffel.S., Scharf.S.J., Higuchi,R., Horn,G.T., Mullis.K.B. and Erlich,H.A. (1988) Primer-directed enzymatic amplification of DNA with a thermostable DNA polymerase. Science. 239, 487-491.

Sambrook,J., Fritsch.E.F. and Maniatis,T. (1989) Molecular Cloning: A Laboratory Manual. Cold Spring Harbor Laboratory Press, Cold Spring Harbor, NY.

Sanger.F., Nicklen.S. and Coulson,A.R. (1977) DNA sequencing with the chain terminating inhibitors. Proc. Natl Acad. Sci. USA, 74, 5463-5467.

Staehling,H.K., Hoffmann,F.M., Baylies,M.K., Rushton,E. and Bate,M. (1994) $d p p$ induces mesodermal gene expression in Drosophila. Nature, 372, 783-786.

Studier.F.W. and Moffat,B.A. (1986) Use of bacteriophage T7 RNA polymerase to direct selective high level expression of cloned genes. J. Mol. Biol., 189, 113-130.

Suggs,S.V., Katzowitz,J.L., Tsai,M.C. and Sukhatme,V.P. (1990) cDNA sequence of the human cellular early growth response gene Egr-1. Nucleic Acids Res., 18, 4283.

Sukhatme,V.P. et al. (1988) A zinc finger-encoding gene coregulated with c-fos during growth and differentiation, and after cellular depolarization. Cell, 53, 37-43.

Tautz.D. and Pfeifle.C. (1989) A non-radioactive in situ hybridization method for the localization of specific RNAs in Drosophila embryos reveals translational control of the segmentation gene hunchback. Chromosoma, 98, 81-85.

Volk,T. and VijayRaghavan,K. (1994) A central role for epidermal segment border cells in the induction of muscle patterning in the Drosophila embryo. Development, 120, 59-70.

Williams,G.J.A. and Caveney,S. (1980a) Changing muscle patterns in a segmental epidermal field. J. Embryol. Exp. Morph., 58, 13-33.

Williams,G.J.A. and Caveney,S. (1980b) A gradient of morphogenetic information involved in muscle patterning. J. Embryol. Exp. Morphol., 58, 35-61.

Wilson,C., Pearson,R.K., Bellen,H.J., O'Kane,C.J. Grossniklaus,U. and Gehring,W.J. (1989) P-element-mediated enhancer detection: an efficient method for isolating and characterizing developmentally regulated genes in Drosophila. Genes Dev., 3, 1301-1313.

Received on November 15, 1995; revised on November 29, 1995 